\title{
Uso e conhecimento da aroeira (Myracrodruon urundeuva) por comunidades tradicionais no Semiárido brasileiro
}

Reinaldo Farias Paiva de Lucena ${ }^{1 *}$, Derciopéricles Cavalcanti de Farias ${ }^{1}$, Thamires Kelly Nunes Carvalho ${ }^{1}$, Camilla Marques de Lucena ${ }^{1}$, Carlos Frederico Alves de Vasconcelos Neto ${ }^{1} \&$ Ulysses Paulino de Albuquerque $^{2}$

${ }^{1}$ Laboratório de Etnoecologia, Departamento de Fitotecnia e Ciências Ambientais, Centro de Ciências Agrárias, Universidade Federal da Paraíba, Campus II, s/n, 58397-000, Areia, Paraíba, Brasil.

${ }^{2}$ Laboratório de Etnobotânica Aplicada, Departamento de Biologia, Universidade Federal Rural de Pernambuco, Rua Dom Manoel de Medeiros, s/n, Dois Irmãos, 52171-030, Recife, Pernambuco, Brasil.

\begin{abstract}
Resumo - Neste estudo, buscou-se informações sobre conhecimento e usos tradicionais de Myracrodruon urundeuva, uma espécie ameaçada, em duas comunidades rurais no município de Soledade, estado da Paraíba, Nordeste do Brasil. Foram realizadas entrevistas semiestruturadas com chefes domiciliares, 16 em Barrocas e 28 em Cachoeira, procurando distinguir os usos atuais dos usos potenciais. Com a finalidade de se coletar informações demográficas da população de $M$. urundeuva, foram realizados levantamentos, registrando todos os indivíduos da espécie com circunferência no nível do solo $\geq 3 \mathrm{~cm}$ usos da planta foram distribuídos em sete categorias (subdivididos em madeireiros e não madeireiros, principalmente para construção): forragem, combustível, construção, medicinal, tecnologia, veneno-abortivo e veterinário. Os informantes evidenciaram que coletam ora nas áreas de vegetação de suas propriedades ora nas fazendas vizinhas. Na comunidade de Cachoeira, foram registradas mais citações de uso por homens (89 citações) do que por mulheres (65), enquanto em Barrocas, houve uma equiparidade nesse conhecimento. Nossos resultados sugerem que a notória popularidade e o uso de M. urundeuva vem ameaçando a espécie de extinção local.
\end{abstract}

Palavras-chave adicionais: Brasil, Caatinga, etnobotânica, Nordeste, valor de uso.

\begin{abstract}
Use and knowledge of aroeira (Myracrodruon urundeuva) by traditional communities in the semiarid region of Brazil) - In this study, the traditional knowledge and uses of Myracrodruon urundeuva, an endangered species, were investigated in two rural communities, in the municipality of Soledade, State of Paraíba, northeastern Brazil. Semistructured interviews were conducted with the heads of households, 16 in Barrocas and 28 in Cachoeira, trying to distinguish the current from the potential uses. To collect demographic information on the $M$. urundeuva population, all individuals with circumference at soil level $\geq 3 \mathrm{~cm}$ were recorded in the surveys. Plant uses were classified into seven categories (subdivided into timber and non-timber, especially for construction): forage, fuel, construction, medicine, technology, veterinary and as an abortive. Those interviewed showed that they gather plants either from their own properties or from neighboring farms. In the community of Cachoeira there were more records of use by men (89 citations) than by women (65) whereas in Barrocas records showed equal use by men and women. Our results suggest that the widespread popularity and use of $M$. urundeuva has threatened the species to the verge of local extinction.
\end{abstract}

Additional key words: Caatinga, ethnobotany, Northeast Brazil, use value.

A região do Semiárido nordestino, representado pela caatinga, consiste em um cenário ideal para estudos etnobotânicos, uma vez que compreende uma fascinante diversidade biológica e cultural. Projetos de investigação na região do Semiárido são necessários especialmente à luz da rápida alteração do ambiente, e substituição da vegetação nativa por áreas de cultivo e pastagens (Fernandes 2002; Giullieti et al. 2002; Castelletti et al. 2003), o que tem levado algumas regiões da caatinga a um estado de desertificação (Garda 1996; MMA 1998).

Nessa perspectiva de conservação da biodiversidade, os estudos com enfoque etnobotânico são necessários. Algumas espécies já se encontram em risco de extinção local em várias regiões do Nordeste, como Myracrodruon

\footnotetext{
"Autor para correspondência: reinaldo@cca.ufpb.br

Editora responsável: Ana Haydeé Ladio

Recebido: 17 maio 2011; aceito: 30 ago. 2011.
}

urundeuva Allemão (aroeira), incluída na lista oficial do MMA de espécies ameaçadas de extinção segundo a Instrução Normativa $\mathrm{N}^{\circ} 06$ de 23 de setembro de 2008 (MMA 2008). Além de M. urundeuva, outras espécies da caatinga estão sendo indicadas na literatura como espécies com prioridades locais para ações conservacionistas, tais como Amburana cearensis (Allemão) A.C.Sm. (Cumaru), Anadenanthera colubrina (Vell.) Brenan (Angico), Erythrina velutina Willd.(Mulungu) e Ziziphus joazeiro Mart. (Juazeiro) (Oliveira et al. 2007; Lucena 2009; Albuquerque et al. 2011).

Myracrodruon urundeuva é amplamente utilizada para diversos fins madeireiros e não madeireiros, como medicinal e para a construção de cercas (Albuquerque \& Andrade 2002a,b; Albuquerque \& Lucena 2005; Monteiro et al. 2006; Albuquerque \& Oliveira 2007; Lucena et al. 2007a,b, 2008; Oliveira et al. 2007; Ramos et al. 2008a,b; 
Monteiro et al., 2008; Lucena, 2009), além de estar sendo analisada em estudos de diversas áreas, como a de sistemas agroflorestais, conservação de recursos genéticos, estudos químicos e bioquímicos (Nobre-Júnior et al. 2009; Sá et al. 2009a,b,c; Gaino et al. 2010; Sousa et al. 2010). Nesse estudo, selecionou-se M. urundeuva para verificar se a espécie está sendo utilizada por duas comunidades rurais na microrregião do curimataú paraibano no Nordeste do Brasil e de que forma isso acontece.

\section{Material e Métodos}

Área de estudo. Este estudo foi conduzido nas comunidades rurais de Barrocas e Cachoeira, município de Soledade, estado da Paraíba, Nordeste, Brasil (Figura 1). A região possui clima semiárido quente (BShs segundo KÖPPEN), com precipitação anual em torno de $300 \mathrm{~mm}$, com até 11 meses de seca (Atlas Geográfico do Estado da Paraíba 1985). O município de Soledade está inserido na mesorregião do Agreste e microrregião do Curimataú Ocidental da Paraíba, e possui uma das menores precipitações pluviométricas do Nordeste (SEBRAE 1998). Sua área territorial é de $634,9 \mathrm{~km}^{2}$ e está localizada nas coordenadas
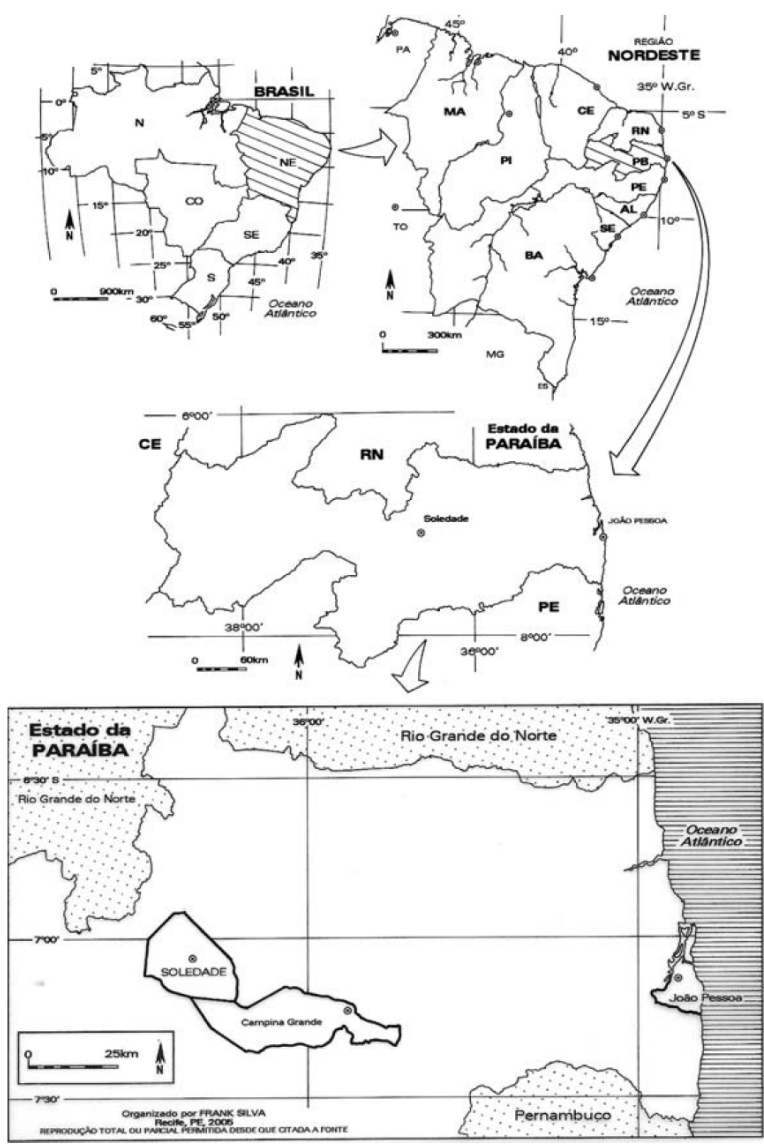

Figura 1. Localização do município de Soledade, estado da Paraíba, Brasil (Sá e Silva et al. 2008).
703'26”' 36 3021'46”'W, com altitude de $521 \mathrm{~m}$. Está próxima às rodovias PB-176 e PB-177, sendo cortada pela BR-230, que dá acesso direto, rumo a oeste, à capital do estado, João Pessoa (186,2 km) (SEBRAE 1998).

A vegetação que predomina na região é hiperxerófila do tipo arbustivo-arbórea, com destaques para árvores como: Erythrina velutina Willd. (mulungu), Schinopsis brasiliensis Engl. (baraúna), Ceiba glaziovii (Kuntze) K.Schum (barriguda), e arbustos como, Aspidosperma pyrifolium Mart. (pereiro), Croton blanchetianus Baill. (marmeleiro) e uma grande quantidade de cactáceas, hoje predominantes em decorrência das grandes derrubadas de espécies arbóreas para a produção de energia (carvão e lenha). O solo é predominantemente halomórfico (contém um alto índice de salinidade), prejudicando os projetos de utilização da água do seu subsolo (SEBRAE 1998).

Comunidades estudadas. $O$ estudo foi realizado nas comunidades rurais de Barrocas e Cachoeira, a cerca de 18 $\mathrm{km}$ do centro urbano do município e faz parte de um projeto maior nessas comunidade, que esta sendo desenvolvido em parceria pelo Laboratório de Etnoecologia da Universidade Federal da Paraíba e o Laboratório de Etnobotânica Aplicada da Universidade Federal Rural de Pernambuco (Sá e Silva et al. 2008; Lucena 2009; Almeida et al. 2010).

Em Barrocas, são encontradas 12 residências habitadas e, em Cachoeira, 18. Nesta última, existe um campo de futebol, três bares e uma Igreja Católica em construção (Sá e Silva et al. 2008; Lucena 2009). Devido à escassez de chuvas na região, por meio de uma ação governamental, foram construídas cisternas em todas as residências de ambas as comunidades para captação de águas da chuva, eventualmente abastecidas com carros pipas trazidos pelo exército brasileiro (Lucena 2009).

Os jovens dessas comunidades devem se deslocar para a cidade para estudarem nos colégios estaduais e municipais. Muitos moradores trabalham como diaristas em fazendas locais e em outras comunidades vizinhas. Algumas mulheres ainda trabalham como auxiliares de serviço geral nas escolas do município e como domésticas nas fazendas da região (Lucena 2009).

A vegetação em ambas as comunidades é semelhante, predominando um estrato arbustivo-herbáceo, com predomínio arbóreo nas margens de rios. Encontram-se muitas espécies de cactáceas e bromeliáceas, as quais são utilizadas na alimentação animal nos períodos de longa estiagem (Lucena 2009). Com relação às espécies lenhosas, existe um predomínio nas duas comunidades de espécies como Croton blanchetianus, Poincianela pyramidalis Tul. (catingueira) e Aspidosperma pyrifolium Mart.

Inventário etnobotânico. Os dados etnobotânicos foram coletados por pesquisadores dos laboratórios acima citados por meio de entrevistas semiestruturadas (Albuquerque et al. 2010), realizadas de agosto de 2006 a março de 2008. Em 2006, um dos autores do presente artigo 
passou todo o ano em convivência diária com os informantes, e nos anos de 2007 e 2008 as visitas foram mais esporádicas, com intervalo médio de dois a três meses, ficando nas comunidades em torno de três a cinco dias por viagem.

Em Barrocas, foram visitadas 10 das 12 residências; um morador se negou a participar da pesquisa e outro faleceu no decorrer do trabalho. Já em Cachoeira, todas as 18 famílias residentes na comunidade participaram da pesquisa. $\mathrm{O}$ objetivo do estudo foi explicado para cada informante e, em seguida, eles foram convidados a assinar o Termo de Consentimento Livre e Esclarecido, segundo resolução do Conselho Nacional de Saúde por meio do Comitê de Ética em Pesquisa (Resolução 196/96).

Os informantes da pesquisa foram os chefes domiciliares, considerando-se tanto o homem como a mulher, sendo 16 em Barrocas ( 8 homens e 8 mulheres) e 28 (13 homens e 15 mulheres) em Cachoeira. A diferença entre o número de homens e mulheres se deu porque ora o entrevistado foi só o homem ora só a mulher, em virtude principalmente dos mesmo serem viúvos(as) ou solteiros(as).

O formulário utilizado nas entrevistas abordou perguntas específicas sobre $M$. urundeuva, visando elucidar seus usos locais, bem como as categorias nas quais eles poderiam se enquadrar. As categorias foram determinadas de acordo com a literatura (Ferraz et al. 2006; Lucena et al. 2008; Lucena 2009), sendo elas: combustível, construção, tecnologia, forragem, medicinal, venenoabortiva e veterinário. Nas entrevistas, buscou-se identificar e diferenciar os usos atuais, aqueles em que a pessoal efetivamente utiliza a planta, dos usos potenciais, aqueles conhecidos pelo informante, porém não utilizado por ele; no entanto, o uso geral, forma comumente utilizada na literatura, não faz distinção entre uso e conhecimento (Lucena 2009).

Durante as entrevistas, procurou-se evitar a influência direta de outras pessoas. As entrevistas foram realizadas individualmente e em horários diferentes (Philips \& Gentry 1993). As informações foram enriquecidas e confirmadas com a utilização de outras técnicas investigativas como a observação direta e a turnê guiada (Albuquerque et al. 2010). A turnê guiada consistiu em um passeio pelas casas e matas das comunidades, com 10 informantes que se dispuseram a colaborar nessa etapa da pesquisa, visando assim identificar a espécie escolhida para esse estudo.

A coleta do material botânico para identificação científica foi realizada com a ajuda de informantes das comunidades. Sendo as mesmas processadas em campo e conduzidas para o Laboratório de Etnobotânica Aplicada para tratamento, identificação e incorporação ao acervo do Herbário Vasconcelos Sobrinho da Universidade Federal Rural de Pernambuco, com duplicatas depositadas no Herbário da Universidade Estadual da Paraíba.

Manejo e disponibilidade local. Para caracterizar a estrutura populacional de $M$. urundeuva, foram realizadas amostragens vegetacionais nas duas comunidades com a finalidade de coletar informações demográficas. Em cada levantamento, foram registrados todos os indivíduos que apresentaram caule com Diâmetro no Nível do Solo (DNS) $\geq$ $3 \mathrm{~cm}$, procedimento utilizado nos estudos realizados na caatinga (Araújo \& Ferraz 2010). Foram alocadas parcelas semipermanentes de $10 \mathrm{~m} \times 10 \mathrm{~m}$, totalizando 100 parcelas e perfazendo uma área total de 1 ha em cada comunidade.

Estimativas da altura dos indivíduos foram realizadas utilizando uma referência padronizada. Todas as análises foram baseadas em indivíduos vivos e íntegros, ou plantas que tinham morrido aparentemente por processos naturais. Foram registrados também informações sobre extrativismo por meio de observação de indivíduos com sinais de corte dentro da área das parcelas. Somado a essas informações, buscou-se, por meio de conversas informais e de entrevistas abertas junto aos moradores e aos informantes principais de cada comunidade, reconhecer os locais de coleta e extração de $M$. urundeuva, bem como as formas de coleta desenvolvidas por eles.

$\mathrm{Na}$ comunidade de Cachoeira, as parcelas foram alocadas na mesma área de mata, formando uma área de 1 ha. Em Barrocas, por questões de disponibilidade regional, as parcelas foram demarcadas em quatro áreas, alocandose 25 parcelas em cada uma. Elas foram montadas em três fazendas com fragmentos de mata, sempre com a permissão dos proprietários.

Os parâmetros fitossociológicos adotados foram área basal, valor de importância, densidade relativa, dominância relativa e frequência relativa, sendo analisados de acordo com Araújo \& Ferraz (2010), em que a Densidade Relativa (DRt, \%) foi estimada pelo número de indivíduos de um determinado táxon com relação ao total de indivíduos amostrados. A Frequência Relativa (FRt, \%) foi estimada com base na FAt (Frequência Absoluta da espécie em questão), em relação à Frequência Total (FT, \%), que representa o somatório de todas as frequências absolutas. A Dominância Relativa (DoRt, \%) representou a porcentagem de DoA (Dominância Absoluta da espécie em questão), com relação à dominância total (DoT). Esses dados foram analisados utilizando o Programa PARAMS, versão 2.0 (Fitopac).

\section{Resultados}

Conhecimento e usos locais. Os informantes das duas comunidades reconheceram diversos usos para $M$. urundeuva, os quais foram distribuídos em sete categorias: forragem, combustível, construção, medicinal, tecnologia, veneno-abortivo e veterinário. Dentro de cada categoria foram atribuídas subcategorias, como por exemplo, lenha e carvão na categoria combustível, e construções rurais e domésticas na categoria construção (Tabelas 1 e 2).

Os usos de $M$. urundeuva foram divididos em 
Tabela 1. Distribuição de citações de uso da aroeira Myracrodruon urundeuva em categorias e subcategorias de usos por moradores da comunidade rural de Barrocas, município de Soledade, estado da Paraíba, Brasil.

\begin{tabular}{|c|c|c|c|c|c|c|c|}
\hline \multicolumn{8}{|c|}{ Barrocas } \\
\hline Categoria & $\begin{array}{l}\text { Número } \\
\text { de } \\
\text { Citações }\end{array}$ & $\begin{array}{l}\text { Uso } \\
\text { Real }\end{array}$ & $\begin{array}{c}\text { Uso } \\
\text { Potencial }\end{array}$ & Subcategoria & $\begin{array}{l}\text { Número } \\
\text { de } \\
\text { Citações }\end{array}$ & $\begin{array}{c}\text { Uso } \\
\text { Atual }\end{array}$ & $\begin{array}{c}\text { Uso } \\
\text { Potencial }\end{array}$ \\
\hline Forragem & 04 & 03 & 01 & - & - & - & - \\
\hline \multirow[t]{2}{*}{ Combustível } & 15 & 03 & 12 & Lenha & 09 & 03 & 06 \\
\hline & & & & Carvão & 06 & - & 06 \\
\hline \multirow[t]{3}{*}{ Construção } & 34 & 08 & 26 & Estaca & 14 & 04 & 10 \\
\hline & & & & Linha & 15 & 11 & 04 \\
\hline & & & & Mourão & 09 & 04 & 05 \\
\hline Medicinal & 10 & 06 & 04 & & - & 06 & 04 \\
\hline Veterinário & 02 & 02 & - & & - & 02 & - \\
\hline \multirow[t]{6}{*}{ Tecnologia } & 20 & - & 20 & $\begin{array}{l}\text { Torno de } \\
\text { Parede }\end{array}$ & 11 & - & 11 \\
\hline & & & & Canga I & 01 & - & 01 \\
\hline & & & & Canga II & 01 & - & 01 \\
\hline & & & & Ferramentas & 04 & - & 04 \\
\hline & & & & Móveis & 02 & - & 02 \\
\hline & & & & Outros & 01 & - & 01 \\
\hline $\begin{array}{l}\text { Veneno } \\
\text { Abortivo }\end{array}$ & - & - & - & - & - & - & - \\
\hline Outros & - & - & - & - & - & - & - \\
\hline
\end{tabular}

madeireiros e não madeireiros com predomínio do uso madeireiro ( $82 \%$ em Barrocas e $84 \%$ em Cachoeira), principalmente na categoria construção. Contudo, com a distinção de uso atual do uso potencial percebeu-se uma diminuição considerável do uso real dessa espécie, tendose apenas $18 \%$ de utilização para fins madeireiros e $10 \%$ para não madeireiros na comunidade de Cachoeira. Já em Barrocas, ambas as categorias obtiveram $13 \%$ de citações de uso atual. Mesmo com a distinção realizada, ainda há um predomínio de usos madeireiros nas comunidades estudadas. Esse destaque se dá pela utilização de $M$. urundeuva nas construções de cerca, visto que sua madeira é utilizada como estaca e mourão.

$\mathrm{Na}$ distinção entre usos atuais e usos potenciais, os resultados do Teste $G$ evidenciaram diferenças significativas, tanto em Barrocas (Teste-G Williams = 238.428; $\mathrm{p}=0,0002)$ como em Cachoeira (Teste-G Williams = 248.555; $\mathrm{p}=0,0001)$, considerando o somatório das citações de todas as categorias.

$\mathrm{Na}$ categoria combustível, registraram-se 15 indicações em Barrocas, sendo seis para carvão e nove para lenha. Dessas, 12 foram de uso potencial e três de uso atual (lenha). Já em Cachoeira obteve-se 31 citações distribuídas em 16 para lenha e 15 para carvão. Em Cachoeira, assim como em Barrocas, as indicações para uso do carvão foram de uso potencial, sendo as de uso real apenas para a Sitientibus série Ciências Biológicas 11(2): 255-264. 2011. subcategoria lenha, que das 16 indicações, 13 foram de uso atual.

A categoria tecnologia se subdividiu em cinco subcategorias em ambas as comunidades: torno de parede, canga I (uso em carroça de boi), canga II (uso em cultivador), cabos para ferramentas e outros usos. A subcategoria torno de parede foi a mais expressiva em Barrocas, obtendo 55\% das citações. Já em Cachoeira, a utilização de $M$. urundeuva foi mais direcionada à fabricação de cabos de ferramentas, como exemplo os cabos para machado $(43,5 \%)$. Os usos dentro dessa categoria, apesar de terem sido bem citados nas duas comunidades, restringem-se ao domínio cognitivo das pessoas, apresentando apenas $10 \%$ de uso atual na comunidade Cachoeira e nenhum uso atual em Barrocas. Dentro de outros usos foram incluídas as citações de uso dessa espécie para a fabricação de móveis, ancoretas (utensílio utilizado para transportar água em cima de animais), pilão para preparo de temperos de cozinha e cachimbos para fumar.

A categoria construção foi dividida em construções rurais (estaca e mourão) e construções domésticas (linha). A utilização de $M$. urundeuva para a fabricação de linhas de telhado de casas parece estar fortemente relacionada a usos passados, em que as pessoas do Semiárido utilizavam com maior frequência os produtos florestais na construção de suas moradias, o que pode ser comprovado nesse estudo, 
Tabela 2. Distribuição de citações de uso da aroeira Myracrodruon urundeuva em categorias e subcategorias de uso por moradores da comunidade rural de Cachoeira, município de Soledade, estado da Paraíba, Brasil.

\begin{tabular}{|c|c|c|c|c|c|c|c|}
\hline \multicolumn{8}{|c|}{ Cachoeira } \\
\hline Categoria & $\begin{array}{l}\text { Número } \\
\text { de } \\
\text { Citações }\end{array}$ & $\begin{array}{l}\text { Uso } \\
\text { Real }\end{array}$ & $\begin{array}{c}\text { Uso } \\
\text { Potencial }\end{array}$ & Subcategoria & $\begin{array}{l}\text { Número } \\
\text { de } \\
\text { Citações }\end{array}$ & $\begin{array}{c}\text { Uso } \\
\text { Atual }\end{array}$ & $\begin{array}{c}\text { Uso } \\
\text { Potencial }\end{array}$ \\
\hline Forragem & 06 & 05 & 01 & - & - & - & - \\
\hline \multirow[t]{2}{*}{ Combustível } & 31 & 13 & 18 & Lenha & 16 & 13 & 3 \\
\hline & & & & Carvão & 15 & - & 15 \\
\hline \multirow[t]{3}{*}{ Construção } & 57 & 13 & 44 & Estaca & 18 & 06 & 12 \\
\hline & & & & Linha & 22 & 01 & 21 \\
\hline & & & & Mourão & 17 & 06 & 11 \\
\hline Medicinal & 16 & 10 & 06 & - & - & - & - \\
\hline Veterinário & 03 & 01 & 02 & - & - & - & - \\
\hline \multirow[t]{6}{*}{ Tecnologia } & 39 & 04 & 35 & Torno de Parede & 10 & - & 10 \\
\hline & & & & Canga I & 04 & 01 & 03 \\
\hline & & & & Canga II & 03 & 01 & 02 \\
\hline & & & & Ferramentas & 17 & 02 & 15 \\
\hline & & & & Móveis & - & - & - \\
\hline & & & & Outros & 05 & - & 05 \\
\hline $\begin{array}{l}\text { Veneno } \\
\text { Abortivo }\end{array}$ & 01 & - & 01 & - & - & - & - \\
\hline Outros & 01 & - & 01 & - & - & - & - \\
\hline
\end{tabular}

no qual as citações de uso potencial foram de $100 \%$ em Barrocas e 95,4\% em Cachoeira. Já com relação à construção de cercas, foram registrados usos atuais, nas duas comunidades, tanto para a confecção de estacas $(28,6 \%$ de uso atual em Barrocas e 33,4\% em Cachoeira) como para mourão $(44,5 \%$ de uso atual em Barrocas e $35,3 \%$ em Cachoeira).

Foram registradas 16 citações de uso de M. urundeuva para fins medicinais em Cachoeira (6 de uso potencial e 10 de uso atual) e $10 \mathrm{em}$ Barrocas (4 de uso potencial e 6 de uso atual) (Tabelas 1 e 2). Em Barrocas, os informantes mencionaram utilizar essa espécie para o tratamento de oito doenças, como inflamações gerais, inflamação de útero, inflamação de intestino, ferimentos externos, infecções gerais, dor e antibiótico, preparando os remédios com a casca (80\%) e a entrecasca (20\%), em forma de garrafada (50\%) (preparo com outras plantas) e molho (50\%) (a parte utilizada é mergulhada em água). Já em Cachoeira, o elenco de doenças tratadas com $M$. urundeuva foi obteve 13 indicações, sendo evidenciadas: coluna, afinar o sangue (colesterol), dor de estômago, dor de rins, ferimento externo, inflamações gerais, inflamação na garganta, inflamação do ovário, inflamação do útero, inflamação da vagina e pancada, utilizando para o preparo dos remédios praticamente só a casca (94\%), com apenas uma indicação de uso de folha (6\%) para o tratamento de ferimento. As formas de preparo foram molho $(57,90 \%)$, garrafada com água $(26,30 \%$ das citações) e banho de assento, garrafada com cachaça e uso tópico, com uma indicação cada uma, correspondendo a $5,26 \%$.

$\mathrm{Na}$ categoria veterinária, foram registradas apenas duas citações em Barrocas (de uso atual) e três em Cachoeira ( 2 de uso potencial e 1 de uso atual). Esse uso é destinado ao tratamento de inflamações gerais e para desocupar o parto do gado bovino (limpar o útero da vaca após o parto).

A categoria forragem foi identificada na utilização das folhas de M. urundeuva para a alimentação dos rebanhos, principalmente do gado bovino e caprino, sendo registradas quatro citações de uso na comunidade de Barrocas (3 de uso atual e 1 de uso potencial), e seis citações em Cachoeira ( 5 de uso atual e 1 de uso potencial).

A utilização de $M$. urundeuva na categoria venenoabortiva não foi bem documentada. Perguntar sobre plantas que provocam aborto em mulheres pode ter inibido os informantes e houve uma única indicação de uso potencial na comunidade de Cachoeira. A informante mencionou que o aborto é provocado bebendo a água dessa planta, a qual é preparada com as cascas colocadas em molho durante alguns dias.

Manejo e disponibilidade local. Os informantes evidenciaram que coletam $M$. urundeuva ora nas áreas de vegetação de suas propriedades rurais ora nas áreas 
pertencentes a vizinhos ou amigos da comunidade. Em Cachoeira, em média, 50\% dos entrevistados disseram que coletam na mata da comunidade e $50 \%$ nas matas dos vizinhos. Já em Barrocas, $100 \%$ dos entrevistados disseram que coletam em suas matas. Essas informações de coleta estão relacionadas ao uso efetivo da planta, desconsiderando-se nessa análise os usos potenciais. Contudo, por meio de conversas informais e caminhadas nos fragmentos florestais com alguns informantes, percebeu-se, de forma informal, que não há uma zona específica de extração da madeira, porém, quando o uso é destinado à fabricação de um medicamento, eles preferem locais de vegetação que não estejam próximos às estradas e nem às residências.

Durante as entrevistas, os informantes também mencionaram que é muito difícil encontrar indivíduos de $M$. urundeuva nas matas da região, principalmente porque os mesmos foram, em décadas passadas, derrubados para a construção de casas e cercas, e fabricação de carvão. A escassez dessa espécie foi confirmada por meio do estudo fitossociológico realizado em cada comunidade. Em um hectare de vegetação de Barrocas, só três indivíduos foram registrados e apenas um deles estava totalmente íntegro; os outros dois haviam sido completamente cortados para uso, restando apenas o tronco, com menos de $1 \mathrm{~m}$ de altura. Já em Cachoeira, a situação foi ainda mais crítica, pois no hectare inventariado não foi registrado nenhum indivíduo vivo, apenas três troncos cortados. Essa situação ecológica de $M$. urundeuva pode ser confirmada na análise fitossociológica, que apresentou Densidades $(0,09 \mathrm{em}$ Barrocas e 0,27 em Cachoeira), Dominâncias $(0,27 \mathrm{em}$ Barrocas e 0,31 em Cachoeira) e Frequências Relativas (0,54 em Barrocas e 0,67 em Cachoeira) muito baixas da planta. $\mathrm{O}$ indivíduo íntegro registrado na área de vegetação estudada em Barrocas apresentou uma $12 \mathrm{~m}$ de altura, os demais registros, incluindo aqueles nas parcelas de Cachoeira não alcançaram $1 \mathrm{~m}$ de altura.

Conhecimento de homens e mulheres. Na comunidade de Cachoeira, registraram-se mais citações de uso de $M$. urundeuva por homens (89 citações) do que por mulheres (65 citações). Já em Barrocas, houve uma equiparidade com relação ao conhecimento dos usos dessa espécie, 47 citações de homens e 44 de mulheres. Quando analisadas as citações distintamente, observa-se uma mudança. Em Cachoeira, por exemplo, têm-se uma igualdade com relação aos usos potenciais, obtendo-se em média, 55 citações para homens e 53 para mulheres, já quando se observa só os usos efetivos, que estão sendo desenvolvidos na prática, tem-se 34 citações para homens e apenas 12 para mulheres. Um fato interessante nessa separação é que, das citações atuais das mulheres, cerca de $42 \%$ estão relacionadas a usos medicinais e $33 \%$ a usos como lenha para abastecer os fogões domésticos, ou seja, $75 \%$ das citações relacionadas a atividades que a literatura aponta como domínio feminino. Já no caso dos homens, $71 \%$ das suas citações de usos efetivos estão relacionados a categorias madeireiras (32,5\% para construções, $26,5 \%$ para combustível e $11,8 \%$ para usos tecnológicos). Já no uso medicinal, diferentemente das mulheres, os homens só participaram com $15 \%$ de citações.

Em Barrocas, quando consideradas apenas citações de uso atual, as mulheres mantiveram a mesma realidade encontrada em Cachoeira, com 50\% de citações voltadas para uso medicinal, e $25 \%$ para uso como lenha nos fogões. Já os homens obtiveram cerca de $60 \%$ de citações de usos madeireiros (48\% na construção e $12 \%$ como combustível), repetindo o quadro encontrado em Cachoeira.

\section{Discussão}

Conhecimentos e usos. $A$ aroeira Myracrodruon urundeuva é amplamente conhecida e utilizada no Nordeste, principalmente pelo fato de ser bastante procurada como produto fitoterápico (Albuquerque \& Andrade 2002a,b; Almeida et al. 2006; Ferraz et al. 2006; Silva et al. 2006; Florentino et al. 2007; Lucena et al. 2007a,b, 2008; Oliveira et al. 2007; Nascimento et al. 2008; Ramos et al. 2008a,b; Sá e Silva et al. 2008; Albuquerque et al. 2009; Lucena 2009; Pereira 2009; Monteiro \& Albuquerque 2010). Ela pode ser utilizada como medicinal, em construções, como planta ornamental, na restauração florestal, em sistemas agroflorestais, na apicultura e em aplicações industriais, como curtumes, pelo seu elevado teor de tanino (Maia 2004). Apesar do maior conhecimento de M. urundeuva ser no uso medicinal, no presente estudo, os atributos medicinais desta espécie foram secundários, visto que os usos madeireiros se sobressaíram, principalmente na construção de cercas e em sua utilização como combustível (lenha). Assim como nas comunidades de Soledade, a utilização dessa espécie em construções de cercas foi registrado por Nascimento et al. (2008) em uma comunidade rural do Semiárido pernambucano, no município de Caruaru, na qual foi registrado um número elevado de indivíduos de $M$. urundeuva nas cercas da comunidade.

O uso dessa espécie predominantemente para fins madeireiros, como apontado acima, deve-se ao fato de sua madeira ser resistente ao apodrecimento e ao ataque de cupins de madeira seca, além de ser quase que imputrescível ao contato com o chão (Maia 2004). Em conversas informais e com visualizações in loco nas cercas das comunidades, pode-se observar que a maior parte das estacas e mourões de $M$. urundeuva presente eram bastante antigas, já apresentando sinais de desgaste ambiental, e os próprios informantes mencionavam que uma estaca ou mourão confeccionado do cerne é capaz de durar até cerca de 100 anos, informações estas também registradas em outras localidades (Maia 2004).

Pelo fato de M. urundeuva apresentar madeira de boa qualidade não só para a construção de cercas, mas também para a construção de casas, sendo utilizada como linhas, a 
mesma foi ao longo dos anos, dizimada da vegetação nativa, o que a colocou em risco de extinção. Em outros casos, como verificou Sampaio (2002), em uma derrubada de vegetação de caatinga, geralmente as pessoas mantêm $M$. urundeuva intacta justamente por sua possível utilização nas construções rurais e domésticas, apesar desse corte ser proibido pela lei.

Além do uso para construção, Sá e Silva et al. (2008) também evidenciaram que nas comunidades de Barrocas e Cachoeira, a $M$. urundeuva também é fortemente usada como combustível, principalmente para lenha de fogões domésticos. Porém, como no presente estudo, houve uma distinção entre uso atual e uso potencial, observou-se que, no caso do uso para lenha, a comunidade de Cachoeira apresentou usos efetivos, já em Barrocas esse uso se mostrou bem menos expressivo.

O uso medicinal, mesmo não sendo madeireiro, tem trazido consequências e ameaças à população de $M$. urundeuva no Nordeste, levando à extinção local em algumas regiões, devido a uma grande quantidade de cascas retiradas para atender a demanda do mercado de fitoterápicos, tantos nos mercados informais e feiras livres, como em mercados industrializados e farmácias de manipulação (Albuquerque et al. 2007). Algumas pesquisas têm registrado grandes quantidades de casca dessa espécie nos mercados públicos, mas especificamente, na parte destinada ao comércio de plantas e animais medicinais (Almeida \& Albuquerque 2002; Albuquerque et al. 2007).

Em Barrocas, foram sete indicações de uso terapêutico para M. urundeuva, e em Cachoeira, foram 11. Almeida et al. (2010) realizou uma pesquisa específica com plantas medicinais nessas comunidades, registrando o mesmo número de indicações terapêuticas. Esses números foram baixos quando comparados com os obtidos por Albuquerque et al. (2007), que registraram 24 indicações terapêuticas a partir de 22 artigos científicos.

Em ambas as comunidades, a parte utilizada na preparação dos remédios foi a casca, o que vem sendo confirmado pela literatura (Almeida \& Albuquerque 2002; Albuquerque et al. 2007; Oliveira et al. 2007). Como essa espécie está no domínio da caatinga, a qual sofre variações climáticas e um efeito muito forte da sazonalidade, é natural que as pessoas utilizem a casca, pois ela encontra-se disponível o ano todo, enquanto as folhas só aparecem na época de chuvas.

Nas áreas de vegetação das comunidades estudadas, os indivíduos de $M$. urundeuva são escassos, o que foi comprovado pela sua ausência nas áreas inventariadas neste estudo, como apresentado nos resultados. Contudo, a planta foi encontrada durante caminhadas livres em outras partes da vegetação. São nessas áreas que os informantes buscam as partes necessárias para seus usos. Para uso como lenha, galhos mortos e caídos no chão são recolhidos, e para o uso medicinal, apenas pedaços da casca para a fabricação de remédios são retirados. Para uma caracterização ecológica e determinação da quantidade exata de indivíduos de $M$. urundeuva presentes nas matas da região, são necessários estudos mais específicos. Em conversas informais, os informantes também evidenciaram que vão buscar tal recurso nas matas das comunidades vizinhas, principalmente para fins medicinais. Outro aspecto a ser analisado com mais acuidade, é a quantidade de madeira extraída dessa espécie para os devidos fins utilitários, o qual não foi realizado no presente estudo por questões logísticas.

Conhecimento de homens e mulheres sobre Myracrodruon urundeuva. Os resultados encontrados nas comunidades de Soledade evidenciaram uma distinção com relação ao domínio cultural e a utilização de $M$. unrundeuva por homens e mulheres, destacando-se usos madeireiros no conhecimento dos homens e usos não madeireiros no domínio das mulheres, tendência essa que vem sendo apresentada na literatura (Luoga et al. 2000; Lacuna-Richman 2004; Lawrence et al. 2005).

O domínio das mulheres na categoria medicinal, como observado no presente estudo, também foi apontado por Taita (2003), que enfatiza que as mulheres possuem um conhecimento mais aprimorado com relação a plantas medicinais e frutíferas, e os homens estão mais envolvidos com usos madeireiros, fato este também observado em Soledade. Luoga et al. (2000) também registrou um maior conhecimento dos homens com relação a usos madeireiros, principalmente na fabricação de carvão. Alguns autores (Figueiredo et al. 1993; Lacuna-Richiman 2004) procuram justificar essa distinção no conhecimento e uso de espécies vegetais a partir do cotidiano das pessoas, no qual os homens tendem a ter um contato diário com espécies vegetais encontradas nas florestas e as mulheres com espécies disponíveis nos quintais e proximidades das residências. Contudo, essa tendência dos homens se especializarem em usos madeireiros e as mulheres em usos não madeireiros não deve ser generalizada e Matavele e Habib (2000) registraram um conhecimento semelhante entre homens e mulheres, principalmente no uso de plantas para fins medicinais.

Implicações para a conservação. Seguindo essa linha de pensamento, buscou-se determinar as formas de conhecimento e uso de $M$. urundeuva, fazendo uma distinção direta do que seria conhecimento (uso potencial) e uso efetivo (uso atual). Essa distinção vem sendo apontada na literatura como essencial para o cálculo do valor de uso e para determinar com maior precisão a possível pressão extrativista de determinadas espécies (Albuquerque \& Lucena 2005). Essa separação se mostrou importante, pois o uso madeireiro atual de $M$. urundeuva (13-18\%) foi substancialmente menor que o potencial $(80 \%)$ nas duas comunidades estudadas.

Os dados encontrados em Soledade são de grande importância para tomadas de decisões sobre a conservação de M. urundeuva e devem ser vistos com atenção, buscando 
uma triangulação com outras fontes de dados. Se fossem levadas em consideração as informações gerais dos informantes, estar-se-ia diante de uma grande pressão extrativista dessa espécie, principalmente para usos madeireiros, o que indicaria imediatas ações de conservação. Contudo, observou-se que grande parte das atribuições utilitárias de $M$. urundeuva fazem parte apenas do conhecimento dos moradores, sem estarem sendo efetivamente utilizada. Com isso, supõe-se que a pressão de uso sobre essa planta atualmente não é tão grande quanto poderia ser ou quanto foi no passado, já que não foi registrado praticamente nenhum individuo vivo e integro da espécie na vegetação inventariada.

Os resultados deste estudo sugerem que a notória popularidade e o uso parcial ou total dos recursos naturais disponibilizados pela aroeira $M$. urundeuva vem lhe trazendo ameaças de extinção local. Diante dessa perspectiva, algumas questões emergem: o uso constante de $M$. urundeuva diminui nas comunidades estudadas porque essa espécie está rara na vegetação local ou porque a substituíram por outras plantas de uso similar? E, se a substituíram, foi por que ela não existe mais ou por que os usuários se depararam com outras plantas de melhor qualidade? Essas perguntas devem ser respondidas para que se tenha uma compreensão mais acurada da real pressão de uso sobre M. urundeuva, podendo auxiliar em planos de manejo e no uso sustentável da espécie e, consequentemente, na sua conservação.

\section{REFERÊNCIAS}

Albuquerque, U.P. \& Andrade, L.H.C. 2002a. Conhecimento botânico tradicional e conservação em uma área de Caatinga no estado de Pernambuco, Nordeste do Brasil. Acta Botanica Brasilica 16: 273-285.

Albuquerque, U.P. \& Andrade, L.H.C. 2002b. Uso de recursos vegetais da Caatinga: o caso do agreste do estado de Pernambuco (Nordeste do Brasil). Interciencia 27: 336-345.

Albuquerque, U.P. \& Lucena, R.F.P. 2005. Can apparency affect the use of plants by local people in Tropical Forests? Interciencia 30(8): 506-511.

Albuquerque, U.P. \& Oliveira, R.F. 2007. Is the use-impact on native caatinga species in Brazil reduced by the high species richness of medicinal plants? Journal of Ethnopharmacology 113: $156-170$.

Albuquerque, U.P.; Medeiros, P.M.; Almeida, A.L.S.; Monteiro, J.M.; Lins Neto, E.M.F.; Melo, J.G. \& Santos, J.P. 2007. Medicinal plants of the caatinga (semi-arid) vegetation of NE Brazil: a quantitative approach. Journal of Ethnopharmacology 114: 325-354

Albuquerque, U.P.; Araujo, T.A.S.; Ramos, M.A.; Nascimento, V.T.; Lucena, R.F.P.; Monteiro, J.M.; Alencar, N. \& Araújo, E.L. 2009. How ethnobotany can aid biodiversity conservation reflections on investigations in the semi-arid region of NE Brazil. Biodiversity and Conservation 18: 127150.

Albuquerque, U.P.; Lucena, R.F.P. \& Alencar, N.L. 2010. Métodos e técnicas para coleta de dados etnobiológicos. In: U.P. Albuquerque, R.F.P. Lucena \& L.V.F.C. Cunha (orgs), Métodos e Técnicas na Pesquisa Etnobiológica e Etnoecológica. NUPEEA, Recife, p. 39-64.

Albuquerque, U.P.; Sieber, S.S.; Caetano de Sá, J.; Soldati, G.T.; Medeiros, P.M. \& Souza, L.C. 2011. Rapid ethnobotanical diagnosis of the Fulni-ô Indigenous lands (NE Brazil): floristic survey and local conservation priorities for medicinal plants. Environment, Development and Sustainability 13: 277-292.

Almeida, C.F.C.B.R. \& Albuquerque, U.P. 2002. Uso e conservação de plantas e animais medicinais no estado de Pernambuco (Nordeste do Brasil): um estudo de caso. Interciencia 27: 276-285.

Almeida, C.F.C.B.R.; Amorim, E.L.C.; Albuquerque, U.P. \&
Maia, M.B.S. 2006. Medicinal plants popularly used in the Xingó region - a semi-arid location in Northeastern Brazil. Journal of Ethnobiology and Ethnomedicine 2: 15.

Almeida, C.F.C.B.R.; Ramos, M.A.; Amorim, E.L.C. \& Albuquerque, U.P. 2010. A comparison of knowledge about medicinal plants for three rural communities in the semi-arid region of northeast of Brazil. Journal of Ethnopharmacology 127: 674-684.

Araújo, E.L. \& Ferraz, E.M.N. 2010. Análise da Vegetação nos Estudos Etnobotânicos. Ed. Viena, Santa Cruz do Rio Pardo, p. 223-254.

Atlas Geográfico do Estado da Paraíba 1985. Secretaria da Educação, Governo do Estado da Paraíba, Universidade Federal da Paraíba, João Pessoa.

Castelleti, C.H.M.; Santos, A.M.M.; Tabarelli, M. \& Silva, M.C.S. 2003. Quanto ainda resta da Caatinga? Uma estimativa preliminar. In: I.R. Leal, M. Tabarelli \& J.M.C. Silva (orgs), Ecologia e Conservação da Caatinga. Ed. Universitária, UFPE, Recife.

Fernandes, A. 2002. Biodiversidade da Caatinga. In: E.L. Araújo, A.N. Moura, E.S.B. Sampaio, L.M.S. Gestinari, \& J.M.T. Carneiro (orgs), Biodiversidade, Conservação e Uso Sustentável da Flora do Brasil. Imprensa Universitária, UFRPE, Recife, p. 42-44.

Ferraz, J.S.F.; Albuquerque, U.P. \& Meunier, I.M.J. 2006. Valor do uso e estrutura da vegetação lenhosa às margens do Riacho do Navio, Floresta, PE, Brasil. Acta Botanica Brasilica 20: 25-134.

Figueiredo, G.M.; Leitão-Filho, H.F. \& Begossi, A. 1993 Ethnobotany of Atlantic Forest Coastal communities: diversity of plant uses in Gamboa (Itacuruçá Island, Brazil). Human Ecology 21: 419-430.

Florentino, A.T.N.; Araújo, E.L. \& Albuquerque, U.P. 2007. Contribuição de quintais agroflorestais na conservação de plantas da Caatinga, município de Caruaru, PE, Brasil. Acta Botanica Brasilica 21(1): 37-47.

Gaiano, A.P.S.C.; Silva, A.M.; Moraes, M.A.; Alves, P.F.; Moraes, M.L.T.; Freitas, M.L.M. \& Sebbenn, A.M. 2010. Understanding the effects of isolation on seed and pollen flow, spatial genetic structure and effective population size of the dioecious tropical tree species Myracrodruon 
R. F. P. Lucena et al. - Conhecimento tradicional da aroeira (Myracrodruon urundeuva)

urundeuva. Conservation Genetics 11: 1631-1643.

Garda, E.C. 1996. Atlas do Meio Ambiente do Brasil. Editora Terra Viva, Brasília.

Giulietti, A.M.; Harley, R.M.; Queiroz, L.P.; Barbosa, M.R.V.; Neta A.L.B. \& Figueiredo, M.A. 2002. Espécies endêmicas da Caatinga. In: E.V.S. Sampaio, A.M. Giulietti, J. Virgínio \& C.F.L. Gamarras-Rojas (eds), Vegetação \& Flora da Caatinga. APNE e CNIP, Petrolina, p. 103-118

Lacuna-Richman, C. 2004. Subsistence strategies of an indigenous minority in the Philippines: non-wood forest product use by Tagbanua of Narra, Palawan. Economic Botany 58: 266-285.

Lawrence, A.; Phillips, O.L.; Reategui, A.; Lopez, M.; Rose, S.; Wood, D. \& Farfan, A.J. 2005. Local values for harvested forest plants in Madre de Dios, Peru: towards a more contextualised interpretation of quantitative ethnobotanical data. Biodiversity and Conservation 14: 45-79.

Lucena, R.F.P. 2009. Avaliando a Diferença de Diferentes Técnicas de Coleta e Análise de Dados para a Conservação da Biodiversidade a partir do Conhecimento Local. Tese de doutorado. Universidade Federal Rural de Pernambuco.

Lucena, R.F.P.; Albuquerque, U.P. \& Araújo, E.L. 2007a. Does the use-value of woody plants of the Caatinga (Northeastern Brazil) explain their local availability? Economic Botany 61(4): 347-361.

Lucena, R.F.P.; Albuquerque, U.P.; Monteiro, J. M.; Almeida, C.F.C.B.R.; Florentino, A.T.N. \& Ferraz, J.S.F. 2007b. Useful plants of the semi-arid northeastern region of Brazil a look at their conservation and sustainable use. Environmental Monitoring and Assessment 125: 281-190.

Lucena, R.F.P.; Nascimeno, V.T.; Araújo, E.L. \& Albuquerque, U.P. 2008. Local uses of native plants in an area of caatinga vegetation (Pernambuco, NE-Brazil). Ethnobotany Research Application 6: 3-13.

Luoga, E.J.; Witkowski, E.T.F. \& Balkwill, K. 2000. Differential utilization and ethnobotany of trees in Kitulanghalo Forest Reserve and surrounding communal lands, Eastern Tanzania. Economic Botany 54: 328-343.

Maia, G.N. 2004. Caatinga: árvores e arbustos e suas utilidades. 1. ed. Ed. D\&Z, São Paulo.

Matavele, J. \& Habib, M. 2000. Ethnobotany in Cabo Delgado, Mozambique: use of medicinal plants. Environment, Development and Sustainability 2: 227-234.

MMA (Ministério do Meio Ambiente) 1998. Desertificação: caracterização e impactos. Ministério do Meio Ambiente, Brasília.

MMA (Ministério do Meio Ambiente) 2008. Instrução Normativa $N^{o}$ 06, de 23 de Setembro de 2008. Ministério de Meio Ambiente. Disponível em http://www.ibama.gov.br/recursosflorestais/documentos/lista-oficial-de-especies-brasileirasameacadas-de-extincao/; acesso em 9 maio 2011.

Monteiro, J.M.; Almeida, C.F.C.B.R.; Albuquerque, U.P.; Lucena, R.F.P.; Florenino, A.T.N. \& Oliveira, R.L.C. 2006. Use and traditional management of Anadenanthera colubrina (Vell.) Brenan in the semi-arid region of northeastern Brazil. Journal Ethnobotany and Ethnomedicine 2: 1-7.

Monteiro, J.M.; Lucena, R.F.P.; Alencar, N.L.; Nascimento, V.T.; Aráujo, T.A.S. \& Albuquerque, U.P. 2008. When intention matters: comparing three ethnobotanical data collection strategies. In: U. P. Albuquerque \& M.A. Ramos (orgs), Current Topics in Ethnobotany. Research Signpost,
Kerala, p. 113-124.

Monteiro, J.M. \& Albuquerque, U.P. 2010. O valor dos recursos naturais e a valoração contingente de Myracrodruon urundeuva Allemão - um enfoque conservacionista. In: U.P. Albuquerque \& N. Hanazaki (orgs), Árvores de Valor e o Valor das Árvores: pontos de conecção. Vol. 8. Ed. Viena, Santa Cruz do Rio Pardo, p. 107-134.

Nascimento, V.T.; Sousa, L.G.; Alves, A.G.C.; Araújo, E.L. \& Albuquerque, U.P. 2008. Rural fences in agricultural landscapes and their conservation in an area of caatinga (dryland vegetation) in Northeast Brazil. Environment, Development and Sustainability 11: 1005-1029

Nobre-Júnior, H.V.; Oliveira, R.A.; Maia, F.D.; Nogueira, M.A.S.; Moraes, M.O.; Bandeira, M.A.M.; Andrade, G.M. \& Viana, G.S.B. 2009. Neuroprotective effects of chalcones from Myracrodruon urundeuva on 6-hydroxydopamineinduced cytotoxicity in rat mesencephalic cells. Neurochemical Research 34: 1066-1075.

Oliveira, R.L.C.; Lins Neto, E.M.F.; Araújo, E.L. \& Albuquerque, U.P. 2007. Conservation priorities and population structure of woody medicinal plants in area of Caatinga vegetation (Pernambuco State, NE Brazil). Environmental Monitoring and Assessment 132: 189-206.

Pereira, D.D. 2009. Mangas Malhadas e Cercados: o Semiárido que não se rende! Impressos Adilson, Campina Grande.

Phillips, O. \& Gentry, A.H. 1993. The useful plants of Tambopata, Peru: I. Statistical hypotheses tests with a new quantitative technique. Economic Botany 47(1): 15-32.

Ramos, M.A.; Medeiros, P.M.; Almeida, A.L.S.; Feliciano, A.L.P. \& Albuquerque, U.P. 2008a. Use and knowledge of fuelwood in an area of caatinga vegetation in NE Brazil. Biomass \& Bioenergy 32: 510-517.

Ramos, M.A.; Medeiros, P.M.; Almeida, A.L.S.; Feliciano, A.L.P. \& Albuquerque, U.P. 2008b. Can wood quality justify local preferences for firewood in an area of caatinga (dryland) vegetation. Biomass \& Bioenergy 32: 503-509.

Sá, R.A.; Argôlo, A.C.C.; Napoleão, T.H.; Gomes, F.S.; Santos, N.D.L.; Melo, C.M.L.; Albuquerque, A.C.; Xavier, H.S.; Coelho, L.C.B.B.; Bieber, L.W. \& Paiva, P.M.G. 2009a. Antioxidant, fusarium growth inhibition and Nasutitermes corniger repellent activities of secondary metabolites from Myracrodruon urundeuva heartwood. International Biodeterioration \& Biodegradation 63: 470477.

Sá, R.A.; Santos, N.D.L.S.; Silva, C.S.B.; Napoleão, T.H.; Gomes, F.S.; Cavada, B.S.; Coelho, L.C.B.B.; Navarro, D.M.A.F.; Bieber, L.W. \& Paiva, P.M.G. 2009b. Larvicidal activity of lectins from Myracrodruon urundeuva on Aedes aegypti. Comparative Biochemistry and Physiology, Part C 149: 300-306.

Sá, R.A.; Gomes, F.S.; Napoleão, T.H.; Santos, N.D.L.; Melo, C.M.L.; Gusmão, N.B.; Coelho, L.C.B.B.; Paiva, P.M.G. \& Bieber, L.W. 2009c. Antibacterial and antifungal activities of Myracrodruon urundeuva heartwood. Wood Science Technology 43: 85-95.

Sá e Silva, I.M.M.; Marangon, L.C.; Hanazaki, N. \& Albuquerque, U.P. 2008. Use and knowledge of fuelwood in three rural caatinga (dryland) communities in NE Brazil. Environmental Monitoring and Assessment 11: 114:1-25

Sampaio, E.V.S.B. 2002. Uso das plantas da caatinga. In: E.S.B. Sampaio, A.M. Giulietti, J. Virgínio \& C. Gamarra-Rojas 
(orgs), Vegetação \& Flora da Caatinga. APNE e CNIP, Petrolina, p. 49-90.

SEBRAE (Serviço Brasileiro de Apoio às Micro e Pequenas Empresas) 1998. Soledade. Série Diagnóstico SócioEconômico. Sebrae-PB, Proder, João Pessoa.

Silva, V.A.; Andrade, L.H.C. \& Albuquerque, U.P. 2006. Revising the cultural significance index: the case of the Fulniô in Northeastern Brazil. Field Methods 18(1): 98-108.
Sousa, L.F.; Maurício, R.M.; Moreira, G.R.; Gonçalves, L.C.; Borges, I. \& Pereira, L.G.R. 2010. Nutritional evaluation of "Braquiarão" grass in association with "Aroeira" trees in a silvopastoral system. Agroforest System 79: 189-199.

Taita, P. 2003. Use of woody plants by locals in Mare aux Hippopotames Biosphere reserve in western Burkina Faso. Biodiversity and Conservation 12: 1205-1217. 